$\operatorname{R}_{\text {ESEA }}^{\text {RCH }}$ RTICL

Members of the Research Forum Associate Author :

${ }^{1}$ Department of Veterinary Anatomy and Histology, Ranchi Veterinary College, Kanke, RANCHI (JHARKHAND) INDIA

AUTHOR FOR CORRESPONDENCE : S. MEHTA

Department of Veterinary Anatomy and Histology, Ranchi Veterinary College, Kanke, RANCHI (JHARKHAND) INDIA

\section{Gross morphometric studies on sternum and ribs of emu (Dromaius novaehollandiae)}

\author{
S. MEHTA, RUPAM SINHA ${ }^{1}$ AND K.K. SINGH ${ }^{1}$
}

Abstract : Study was conducted on 3 adult emus to record gross morphometric parameters. The sternum was collected after post mortem examination from Department of Veterinary Pathology, Ranchi Veterinary College Kanke, Ranchi. The sternum of emu was large broad and bowl shaped located at antero-ventral aspect the body cavity. The cranial border was $8.12 \pm 0.8$ $\mathrm{cm}$ broad. The dorsal surface was concave which measured $3.00 \pm 0.12 \mathrm{~cm}$ concavity. The ventral surface was more convex, rough and without keel bone. Antero-lateral process was $2.4 \pm .06 \mathrm{~cm}$ in length which was directed upward. Post extremities or metasternum was thin and triangular in shape. Unlike other birds postero-lateral process was absent. Five pairs of articular facets present on either side for attachment of sternal ribs. Nine pairs of ribs were present. The length of rib were varied from $12.00 \mathrm{~cm}$ to $19.00 \mathrm{~cm}$. The lateral surface was convex while medial surface concave. The cranial and caudal border were smooth and thin. The uncinate processes was absent. The proximal extremities of vertebral rib had head, neck and tubercle. The head was $1.9 \pm 0.30 \mathrm{~cm}$ in length which articulated with the facet of the body of the vertebrae. The average length of tubercle was $3.30 \pm 0.40 \mathrm{~cm}$ and articulated with the surface of the transverse process of the vertebra.

Key words : Sternum, Rib, Emu, Gross morphology

How to cite this paper : Mehta, S., Sinha, Rupam and Singh, K.K. (2017). Gross morphometric studies on sternum and ribs of emu (Dromaius novaehollandiae). Vet. Sci. Res. J., 8(1\&2) : 47-49, DOI : 10.15740/ HAS/VSRJ/8.1and2/47-49.

Paper History : Received : 02.09.2017; Revised : 08.09.2017; Accepted : 23.09.2017 